\title{
Son Preference among the Educated Urban Middle-class in North India
}

\author{
${ }^{1}$ Independent Researcher, NEW ZEALAND \\ Ambika Kohli 1*
}

*Corresponding Author: ako35@uclive.ac.nz

Citation: Kohli, A. (2018). Son Preference among the Educated Urban Middle-class in North India, Journal of Cultural Analysis and Social Change, 3(1), 05. https://doi.org/10.20897/jcasc/3116

Published: August 9, 2018

\begin{abstract}
The prevalence of son preference among different socio-cultural and religious communities in India is an expression of patriarchal culture and values which highlights men's social dominance and women's subordinate position within this society. This qualitative study sheds light on how urban middle-class married mothers in the states of Delhi and Haryana, India, view and practice son preference. I conducted semi-structured interviews with 45 urban married, educated middle-class mothers who were recruited through the technique of snowballing. This research finds son preference to be deemed natural and acceptable by the urban middle-class women interviewed during the course of this study because of the various socio-cultural advantages associated with having a son. Old-age support, enhanced social status, women's social dependency on men are some of the various socio-cultural benefits that participants attributed to the popularity of son preference. However, despite the prevalence of son preference, daughter aversion was not evident among the participants; they provided the same love, care, and education career opportunities to their daughters as they did to their sons. The research concludes that daughters' social status is gradually improving as social attitudes among the urban middle-class are changing. This article suggests that women's acceptance of son preference signifies that they have internalised their own gender subordination to the extent that they consider men to be socio-culturally and biologically superior to them. In order to examine this acceptance of gender subordination by women, I have employed Pierre Bourdieu's concepts of symbolic violence and symbolic capital.
\end{abstract}

Keywords: symbolic violence, dowry, female foeticide, patriarchy, son preference

\section{INTRODUCTION}

Son preference is a patriarchal ideology which favours sons over daughters and has led to the practice of female foeticide in contemporary times. Female foeticide refers to sex-detection of a foetus followed by an abortion if the foetus is found to be female. It is prevalent in many countries such as China, India, South Korea, and Vietnam (George, 1997). China has the lowest female child sex ratio in the world, followed by India. There have been a number of studies conducted at the global level and particularly within Asia which examine this imbalance in female-male sex ratios (Goodkind, 1996; Miller, 1987; Pande, 2003; Unnithan-Kumar, 2005).

While son preference is common in India, it is not practiced uniformly across different class groups (Mitra, 2014). For instance, because of their education, knowledge and financial resources, financially affluent people usually resort to sex-selective abortions and In Vitro Fertilisation (IVF) techniques to have a son while keeping their family size small, often limited to two children (Mitra, 2014; Smith et al., 2008). On the other hand, people with less wealth usually have a higher fertility rate and a higher female child mortality rate, lower female literacy, higher female malnutrition, and are more likely to practice female infanticide in place of female foeticide (Mitra, 2014; Smith et al., 2008). 
I carried out my research in the urban regions of Delhi and Haryana, in the years 2010 and 2011. In this article, I discuss son preference as it is experienced by educated urban married middle-class mothers from the North Indian states of Delhi and Haryana (Yamuna Nagar district). The study explores women's attitudes to son preference and how they frame the issue. The article also elucidates popular reasons for son preference among the urban middle-class. Further, I also examine how women treat their daughters within a rapidly changing social and economic context where son preference remains the cultural norm.

Since the introduction of neoliberal policies in 1980-1990s both Delhi and Haryana have experienced rapid urbanisation and economic growth, with an increase in Business Process Outsourcing (BPO) and Information Technology (IT) industries, and a sharp increase in the building developments, including new shopping malls and modern housing sub-divisions (Chatterji, 2013). I choose Delhi and Haryana because the urban middle-class in these states is facing dramatic socio-cultural and financial changes as a consequence of neoliberal practices. Changes include increased economic development, a higher female literacy rate, women entering into the paid workforce, and a trend away from large numbers of children to nuclear families of one or two children at most.

Interestingly, both Delhi and Haryana have a low female child sex ratio, but have recorded an increase in female literacy. According to the 2011 census, the literacy rate in Delhi and Haryana is above the national average of $65.46 \%$. The female literacy rate in Delhi is $80.93 \%$, and in Haryana, it is $66.77 \%$, whereas for Yamuna Nagar it is $72 \%$ (Census, 2011; Talwar and Meenu, 2014).

Haryana has the lowest female child sex ratio in India, with 834 female children per 1000 male children (Indian Census, 2001). Not even a single district, out of 22, in Haryana is above the national average of 914 females to 1000 males. Similarly, Delhi also ranks low in its female child sex ratio, with 871 girls per 1000 boys (Indian Census, 2001). The urban areas have a lower sex ratio than the rural areas: in 2011 urban regions recorded a female child sex ratio of 902, which was lower than rural areas where it was 919 (Chandramouli, 2011; Indian Census, 2001).

\section{Son Preference in India}

Indian society is mainly patriarchal and patrilineal; that is, men are the heads of families and women join their husbands' families after their marriages. Patriarchal beliefs and values have resulted in different forms of gender inequalities, and despite several socio-cultural and legal reforms, various types of gender inequalities are still persistent in urban India; female foeticide is one such example of gender inequality.

Although female foeticide is illegal under the Pre-Conception and Pre-Natal Diagnostic Techniques (PCPNDT) Act 1994, sex-selective abortions are procured illegally, leading to a constant decline in the female child sex ratio (Patel, 2007; Unnithan-Kumar, 2010). With the introduction of modern reproductive technologies, infanticide has been replaced by foeticide (Indian Census, 2001). Indian historical accounts suggest that female infanticide was common in societies where dowry ${ }^{1}$ was practised, and where only a few women were employed in the agriculture sector (Miller, 1987; Miller, 1997). According to Miller (1997), during the British colonial era in India, female infanticide was widely practised in North West India because of dowry practice. On the other hand, in South India, infanticide was not as prevalent because of women's participation in agricultural activities.

Previously dowry was practiced by high castes as a form of financial support for daughters, as women were restricted from working outside and were not allowed to inherit property (Dalmia et al., 2007, p.73; Srinivasan and Lee, 2004). Women are now legally entitled to inherit their parents' and grandparents' property, but dowry now seems to be a price for a good match (Dalmia et al., 2007). Educated grooms are highly valued and considered to be a good catch. This paradoxically leads to a demand for an increased dowry for the educated and employed bride's family (Dalmia et al., 2007; Munshi, 2012). Dowry practice has not only increased significantly, but it is also now rapidly spreading in areas and communities where it was not prevalent before or where bride price was practised (Agnihotri, 2003; Self and Grabowski, 2009). A study suggests that the more educated married women spend on dowry, the more dowry has become the status quo. As demands for dowry are increasing, brides' families are also providing big, elaborate, modern Indian style weddings to maintain their social status (Brosius, 2011).

In addition to dowry, the popularity of son preference in India could also be attributed to collective patriarchal family values. India has a collective culture in which relationships and family values play a vital role in determining people's choices (Guess, 2004; Konsky et al., 1999). People in India have close social networks and are socially, emotionally, and economically dependent on each other in their daily lives. Since women in India leave their maternal families after their marriages, most parents are financially, emotionally, and socially dependent on their sons in their old age. Therefore, dowry is not the only reason behind son preference, instead financial and old-age support are also some of the essential driving factors (Arnold, 2001; Das Gupta et al., 2003; Unnithan-Kumar, 2010).

The demands for dowry and the seeking of financial, social and emotional support by parents of sons may at first glance seem to suggest that families from lower economical and educational backgrounds are more likely to

\footnotetext{
${ }^{1}$ Dowry is the practice of giving away of material wealth in the form of money or property or jewelry or goods by a bride's family to a groom's family.
} 
practice son preference (Mitra, 2014; Sharma et al., 2007). On the contrary, studies and census figures reveal a link between increasing female literacy rates and declining female child sex ratio (Indian Census, 2001; Sharma et al, 2007; Talwar and Meenu 2014). Educated and employed women from affluent families comprise a significant proportion of the consumers of foeticide services (Patel, 2007). Because of their knowledge and financial status, educated women from wealthy backgrounds can easily access reproductive technologies to obtain sex-selective abortions as they pursue their desire for a son, unlike uneducated women who are unaware of or lack access to such services (Sharma et al., 2007).

Further, the popularity of the modern small family size among the middle-class is also an important reason behind the lower female child sex ratio. Small family size plays a pivotal role in the increased use of ultrasound, and sex-selective abortions as urban educated couples want to have at least one son and also limit their family size to one or two children (Sekher and Hatti, 2010; Unnithan-Kumar, 2010) Therefore, in contemporary urban India son preference is a complex phenomenon where different traditional and modern socio-cultural and economic factors are at play.

\section{THEORETICAL FRAMEWORK}

French sociologist Pierre Bourdieu discussed four types of capital: economic, social, cultural and symbolic capital (Bourdieu, 1986). These capitals are accumulated through labour (Bourdieu, 1986, p.46). Labour in this context can be understood as including social work or actions, such as practising a socio-cultural belief that will help in the accumulation of different forms of capital. Bourdieu's use of the term 'capital' is much broader than monetary gain, and he employs the term 'capital' in the wider system of socio-cultural exchanges. He insists that capital cannot be limited only to monetary achievements, such as wealth, income, property, and other financial assets that indicate one's financial class and status. He argues that capital is also accumulated through social, cultural and symbolic gains (Bourdieu, 1986).

Economic capital signifies money, property, or other financial assets that indicate one's class and status. In this article, economic capital is discussed in relation to dowry, parents investing money on their children, and parents receiving financial support from their children, mainly sons.

Bourdieu explained that, beyond economic capital, cultural habits and dispositions play a crucial role in determining one's class and status. Cultural capital includes forms of knowledge, skills, education, intellect, and knowledge of religion, traditional rituals and customs which simultaneously indicate one's class and status, and simultaneously confer the status (Weininger and Annette, 2007). In this research, cultural capital is considered in the context of urban middle-class collective family values, gender roles, and the gendered division of labour.

Social capital, as discussed by Bourdieu, is discussed as different forms of social and human resources within one's network, used by social actors to achieve their interests and to position themselves (Ihlen, 2005). Social capital signifies having good networks, social connections, relationships, and support from family, friends, and acquaintances which enhances the quality of life at different levels such as professional, social, and individual (Benzanson, 2006). Because daughters join their husbands' families after their marriages most of the mothers interviewed in this research relied on their sons for all sorts of support. Thus, in this study, social capital could be understood as women receiving support from their sons; and brothers and sisters having healthy relationships.

These forms of capital further lead to the accumulation of symbolic capital, which could be understood as prestige, honour, reputation, recognition, and personal authority and refer to the available resources that provide social positioning and recognition to individuals and groups within a society (Bourdieu, 1986; Swartz, 2012). Symbolic capital "functions as an authoritative embodiment of cultural value" (Swartz, 2012, p. 648), and it is a socially constructed process (Bourdieu, 1986) which leads to a common understanding and shared beliefs of "valued, legitimate, valid and useful" resources or practices within a society (Doherty and Dickmann, 2009). In this article, symbolic capital is discussed as the capital acquired by the participants by having a caring son who would provide old-age support and would care for them. All of this provided the participants with social recognition and value among their families and social acquaintances. Because of the cultural, economic, social and eventually symbolic capital conferred by having a son, women viewed son preference as legitimate and normal. I argue that the acceptance of son preference as natural is a manifestation of participants internalising their gender subordination within the patriarchal setting they are accustomed to. By doing so women internalise their lower socio-cultural position and reimpose gender inequality; this could be understood as a form of symbolic violence. In this article, internalisation can be understood as the acceptance of patriarchal socio-cultural beliefs, values, and norms that individuals learn through their experiences of socialisation. Women apply these values and beliefs to themselves and other women and consider men to be socially superior, while regarding themselves as inferior and dependent. Institutions such as family and marriage maintain the norms of gender inequality and reproduce them in daily socio-cultural interactions. 
In this context, Bourdieu and Passeron (1977) introduced the concept of symbolic violence that explains how inequitable gender relations are reproduced and maintained. Jenkins (1993) suggests that through socialisation symbolic violence leads to various ways of thinking and acting being internalised by groups and classes in a way that masks underlying power relations. Symbolic violence is violence because "it leads to the constraint and subordination of individuals, but it also symbolic in the sense that it is achieved indirectly and without overt and explicit acts of force or coercion:" (Connolly and Healy, 2004). Symbolic violence is different from physical abuse and denotes different modes of socio-cultural domination where the complicity of the dominated is a prerequisite (Bourdieu and Wacquant, 2004). The dominated social actors (in this case, women in patriarchal societies) accept and misrecognise the dominance of the social order as natural rather than something which is socially constructed (Bourdieu, 2002; Clark, 2004; Köverová, 2010; Swartz, 2012). Furthermore, symbolic violence legitimises this domination which subordinates social actors placed at the lower level of the social hierarchy (Trammell, 2011, p.307). Groups located at the higher positions in social strata are considered to be advantaged as they not only practice domination over dominated groups but also deny them "access to the same opportunities and privileges." (DiGiorgio, 2009, p. 917). Therefore, symbolic violence is manifested in the way that individuals internalise their subordination to which they are subjected to because of their race, class or gender.

Bourdieu mentioned symbolic violence as a means of reproducing gender hierarchies, in a way that tends to benefit men more than women: this is done without coercion or physical force (Bourdieu, 1990). According to Bourdieu and Wacquant (2004), "the male order is so deeply grounded as to need no justification" (p. 273). Bourdieu and Wacquant (Swartz, 2012) further argue that:

The case of gender domination shows better than any other that symbolic violence accomplishes itself through an act of cognition and of misrecognition that lies beyond or beneath-the controls of consciousness and will (p. 273).

Symbolic violence is a process of social reproduction of inequalities: even though women have equal legal rights, popular culture becomes the site where unequal gender relations are justified (McRobbie, 2009 and 2004).

\section{METHODOLOGY}

During the course of this qualitative study semi-structured interviews were carried out among 45 married and educated middle-class mothers in Delhi and Haryana. The study was approved by the Human Ethics Committee of the University of Canterbury, New Zealand before fieldwork commenced. Informed written consent was obtained from all individual participants included in the study. Further, I highlighted the issue of confidentiality to my participants before the interview process. This information on maintaining confidentiality was provided to the participants both orally as well as through the information sheet. I have preserved the identity of my participants by using pseudonyms. I have changed the identification details of my participants such as their field of work and studies to preserve their anonymity. This was necessary because the participants in this research were located through snowballing technique: changing these markers have made it highly unlikely that one of the recruiters would be able to identify participants through their identification details.

I conducted interviews in Hindi language among educated urban middle-class married women with children who had either had an abortion or whose first child was a daughter. I preferred to interview those middle-class women who had at least some form of formal education because, as discussed earlier, an increased female literacy rate is closely linked with an increased rate of female foeticide (Indian Census, 2001; Sharma et al., 2007; Talwar and Meenu, 2014).

These women have access to and knowledge of ultrasound and sex-selective abortions, which means that family size and gender composition are not an issue of discrepancy between the educated and wealthy couples (Sabarwal et al., 2012). Because of this, it is often argued that the rate of domestic violence against women in the context of son preference among the urban educated middle-class is relatively low (Sabarwal et al., 2012; Srinivasan and Bedi, 2007). Likewise, not a single participant in this study mentioned experiencing any form of physical violence by their husbands or any other family members for not reproducing a son or for any other reason. Therefore, their accounts and experiences around son preference refer to symbolic violence than physical violence.

\section{Profile of the Participants}

Forty-five participants from urban middle-class backgrounds took part in this study. Among the 45 participants, only 16 belong to the non-working group and have never worked in their lives, identifying as housewives. The remaining 29 were doing some form of paid work or had been formerly employed in the public sector or in the private sector in the field of education, law, or medicine, or they had run their own businesses. It is important to note that the working status recorded shows the employment status of the women during the period when they 
were interviewed. Most of the participants had more than primary education; only two participants studied until year five, and the remaining participants either finished their schooling (16 participants) or were highly qualified (27 participants). Some of them were doctors, lawyers, government officers, teachers, or professors or selfemployed and were working in the private and public sectors.

In regards to family size, the majority of the participants met the modern small-family norm of one or two children. For instance, 30 participants had small families: at the time of the interviews 19 participants had two children. Of these 11 had a boy and a girl, five had only two sons, and three had only two daughters. Eleven had only one child, a daughter, at the time of interview ${ }^{2}$. The remaining 15 participants had a family of three or more children, comprising both boys and girls. It is important to mention that all the participants with more than two children described their family size as large. Twenty-one participants lived in a nuclear family, and 24 participants lived in a joint family on a regular basis, at least in some phase of their lives.

All participants began their reproductive lives no earlier than the 1980s, and all had access to safe and legal abortions and contraception. Furthermore, they all were aware of the use of ultrasound for sex-detection purposes since amniocentesis was introduced in India in 1975. Participants who had their children prior to 1994 were able to access ultrasound for sex-detection purpose without facing any legal repercussions as sex-selection was only criminalised after 1994.

In selecting participants, I gave priority to class since after the neoliberal reforms, unlike the pre-independence and early post-independence periods, the middle-class group is not limited to elites and upper caste Hindus and Muslims, and their hegemony is no longer taken for granted (Donner and Neve, 2011). The new middle-class also consists of people from lower rural castes who have now moved socially and financially upward by entering the urban educated professions such as IT or computer sectors (Belliappa, 2013). It is important to note that the new urban middle-class group is diverse in terms of caste and religion, and may not share the same roots as the old middle-class, but it does share many of the same practices and values (Donner and Neve, 2011). Similarities in ideas about gender relations and patriarchal values are common to the new middle-class (Belliappa, 2013; Radhakrishnan, 2009).

All participants came from a middle-class background. In this study, middle-class is defined as those who have more than the basic necessities of life (food, clothes, and shelter) such as a car, mobile phone, laptop, airconditioner, and fridge. Sridharan (2011), based on income earnings, suggests three middle-class groups in India. These include elite middle-class (more than Indian National Rupees [INR] 140,000 per annum [p.a.]), expanded middle-class (from INR 105,000 p.a.) and broadest middle-class (from INR 35,000 p.a.). My participants belonged to the expanded middle-class group. Because of their financial status, all of the participants were able to access different reproductive technologies to achieve their reproductive interests mainly around son preference.

Initially, I approached my acquaintances to ask them if they would be interested in participating (if applicable) or if they could spread the word regarding my research. Out of 45 participants, 43 of them were Hindus, and two were Muslims. Despite being from diverse religious backgrounds, the Muslim participants shared the same ideas around son preference. Research also suggests that son preference is also practised by Indian Muslims (UnnithanKumar, 2010).

\section{FINDINGS}

The first key finding is that the majority of the participants did not challenge the practice of son preference, and many of them were even more eager to have a son than their husbands and extended families. This was because a son was seen to confer various socio-cultural benefits. Some of these benefits are old-age support, protection from social criticism and increased social status.

Interestingly, all of the participants agreed that women's reproductive choices should be free of any form of coercion or violent assault. Even though sex-selection is illegal, and participants were aware of that, the majority of women did not consider pressure to have a son or sex-detection to practice female foeticide as a form of violence towards them or against their daughters or female foetuses. The compliance of this domination was well articulated in many women's accounts. For example, Sheila, in her mid-30s was a post-graduate, and had two sons. She said:

Nothing is illegal or immoral in practising female foeticide everyone practises it.

Similarly, Tulsi in her early 50s, a housewife held a secondary education and had two daughters and one son. Rita was in her 40s, and had four children: three daughters and one son; and Laxmi in her mid-30s was educated and working and had two daughters. Sana was in her 40s, and had one daughter and a son. All of these women's

2 There was no family of one child with a son. 
daughters were either going to the best schools in town or they were highly educated and were working. Despite treating their daughters with love and care their words reveal clear acceptance of the norm of son preference:

Tulsi: Son preference is natural, and you cannot stop that.

Rita: Yes, everyone wants to have a son, it's natural. Everyone in the family would be happy including me it's like the family is complete now [after having the son].

Sana: It is in our culture if the first child is a daughter then second must be a son.

Laxmi: According to me in India, everyone wants to have a son.

Tulsi, Laxmi, Sana, and Rita wanted to have a son. Tulsi, Sana, and Rita had an ultrasound to ensure the sex of the foetus.

Furthermore, the majority of the participants, whether they had sons or not, calmly stated, that women have a strong desire to have a son. Sonia was in her late 20s, Monika was in mid-40s, and Tara was in the early 40s, all of them were highly educated and were working in influential positions. They all had a daughter as their first child. None of these participants were forced to have a son by their families and all of them themselves had a strong desire to have a son. Monika fell pregnant for a second time as she wanted a son. Tara's second child was a son, and she even had an ultrasound for sex-detection in her second pregnancy.

Sonia: women practice son preference because they badly want to have a son.

Monika: because they [women] do not think it is a big deal to practise son preference.

Tara: because from deep inside women always wish to have a son. I think women are actually more eager than men to have sons.

Tara was adamant that she would not have more than two children and was ready to abort her second pregnancy if it had been a female foetus. However, it was a male foetus and after this was confirmed by ultrasound, she continued with her pregnancy and gave birth to her son. Educated and employed urban middle-class women adhere to traditional patriarchal practices by preferring sons instead of challenging this norm.

Interestingly, both forcing women to bring dowry and pressuring them to have a son or obtaining an ultrasound for sex-detection are illegal, but this has had little impact on these practices. Women do actively report against dowry, whereas they are silent on female foeticide. This elucidates the social transformation against dowry violence, but as yet no major transformation is evident in regards to reporting against pressure to have a son. I asked my participants "Why is it when women are beaten or when they are tortured for not bringing enough dowry they report it to the police? But, when they are forced or tortured to have a son then they do not report it to the police?" The majority of the replies that I received demonstrated that the legitimisation of the morality of son preference remains largely unquestioned among the urban middle-class at a socio-cultural level. For example, both Radha and Kaveri obtained an ultrasound for sex-detection purpose and only continued with their respective pregnancies once the sex of the foetus was confirmed as male. They stated:

Radha: Well, I explain you this. Because pressurising women to have a son is not any form of torture on women. Beating and demands for dowry is a form of torture.

Kaveri: [laughter] in that case [dowry] women are getting hurt that is why they call the police. In the other case [bearing a son], they [affinal family] are asking for a son and the son will remain with the mother [will look after the mother] that is why women do not report against son preference cases.

During the interviews, many participants implied in their tone that son preference is acceptable and popular, unlike dowry. The laughter in Kaveri's account indicates this. Radha and Kaveri did not themselves experience any pressure to bring in dowry, but articulated that physical beatings or emotional pressure for dowry are a form of torture.

Dowry is often argued to be one of the most vital reasons for son preference (Unnithan-Kumar, 2010), and a few of the participants who had two or three daughters mentioned that it would be or was challenging to have big weddings. The participants did not consider giving a big wedding and presenting gifts to their daughters and their sons-in-law and their families as a form of dowry. Instead, giving dowry was a vital medium to show and maintain their social status. Only two participants mentioned dowry to be the principal reason behind son preference.

Another participant, Mira who was in her 40s, had two grown-up educated and working daughters in this context commented that:

This is because the woman has to bring dowry from her parents' family, but the son is born in the affinal house [no financial burden on the maternal family].

The dowry system not only puts great financial pressure on women's maternal families but parents also feel that paying dowry is their social duty to protect their daughters from hardship and violence at the hands of their 
affinal families. Often women do not want to put any pressure on their parents and, in the case of son preference, women can themselves deal with the pressure and negotiate.

The participants further highlighted the benefits of old-age support that were ensured by having a son. For instance, participants preferred to have sons because daughters would get married and join their husbands' families. Kiran was in her mid-20s and only had a daughter. Her daughter was going to the best school in the town and was loved and cared for by her and her husband. Despite this, she and her husband both had a strong desire to have a son. She commented that:

His [her husband's] thinking is that when we grow old, then we will be on our own. We should have a son who will live with us and who will support us. We cannot pin any hopes on our daughter. We will provide her education and everything, but she will join her husband's family eventually.

Gender bias is articulated through the experiences of insecurities around old-age support. These gender relations lead to greater reliance on sons than daughters and influence parents' decisions about the gender composition of their children.

Further, the popularity of patriarchal beliefs and values encouraged women to safeguard themselves from social humiliation by having a son. Sana explained that women try to avoid social criticism by having a son.

It is women and not men who actually have a strong desire to have a son, and I believe this. Because it has been embedded [son preference] in our [women] minds within our own cultural settings, women wish more strongly to have sons. So, that no one in society could say anything to them [criticism or taunts] that they only have daughters and no sons. It is gradually changing now [views around son preference] still these views persist.

This quote highlights how women internalise the patriarchal beliefs that reproduce gender hierarchy rather than challenging them. For, instance, a few of my participants mentioned receiving inferior treatment, such as taunts or not being allowed by their acquaintances to participate in certain festivals and rituals such as Ahoi ${ }^{3}$ because they did not have a son. In the majority of these cases, participants' desire to have a son increased after experiencing criticism. Because they tried to improve their status by having a son, they accepted inequality, rather than challenging it or transforming it. For example, Rama a Muslim participant in her 30s, was highly educated and was working in the public sector. She had three children, two daughters, and one son. Rama and her husband were spending a lot of money on their daughters' education and held high career aspirations for them. After being taunted for many years by her affinal family members and social acquaintances, for not being able to have a son, Rama decided to fall pregnant for the third time to have a son. The participant's husband was not initially ready to have a third child because he prefered a family of two children only; however, after prolonged negotiations, he accepted Rama's proposal. Rama narrated an incidence that was a catalyst to increase her urge to have a son. The incident happened at the birth of her second daughter:

At the birth of my second daughter, my elder sister-in-law talked to me in a very strange manner. She said to me "Oh gosh, your second child is also a daughter, and I thought that if you had a son, then I would give you a gold chain". Then I ignored her and said that I did not want her chain.

However, when Rama at last had her son her sister-in-law did not gift her anything. Gold is very expensive, and in India, it is often gifted to women on festivals or during an auspicious event usually by family members or acquaintances. Giving away gold is an important way to express one's love, care, and respect towards women. This highlights how power relations operate within popular culture that women without sons are unworthy of deserving anything precious. This gift demonstrates that a woman provides a gift to the family in bearing a son and can thus expect to receive valuable or expensive items or special respect and attention in exchange for this.

In some cases, women even pressurised their husbands to ensure that they have a son, and when men did not approve of the idea, it made the participants upset and depressed. Mira narrated her personal experience in this context:

I really wanted to have one son. But what is the point in thinking about that issue now? I could not do anything [sadness in her tone] as he [husband] was completely adamant that he would not try for a son. I wanted to take one more chance [to fall pregnant], and there was nothing wrong with it.

The second finding is that mothers explicitly want sons rather than not wanting daughters. Parents treated their daughters as equal to sons and provided them with comparable career and education opportunities. However, mothers wanted to make sure that their daughters bear sons to ensure their future support and security. This was

${ }^{3}$ A fast observed by Hindu women in some regions of North India to ensure the long life of their sons. 
the most important reason behind son preference mentioned by the participants. Sonia wanted to have a son mainly to keep her daughter protected by providing her a brother. Her articulation highlights the importance of this protection:

A son is not important to enhance a woman's status. The status gets enhanced even with the birth of a girl. But it surely creates a safer environment within a family, especially when the parents and sister grow old. It is like that this family has a son. It is the safety concern, rather than the status factor. A daughter does all the same things, but the safety factor is better with having a son, nothing else. We cannot send the daughter out at night time, but a son can go out during the night. For daughters, you have to depend on others [if there is no son in the family], but a son can perform chores more freely. These are the only restrictions for girls that we cannot send them out during the night because of safety concerns.

Sonia, in a similar vein to all the participants in this study, stated that daughters are equal, but at the same time she mentioned that daughters need protection as well as suggesting that they could be vulnerable as victims of different crimes. This is because, in India, especially North India violence against women such as rape, gang rape, and molestation are quite common (Kohli, 2012). Because of this, parents often feel afraid for their daughters and believe that having a male escort; usually a male family member, might provide women safety from these violent crimes. The majority of the participants, who had a strong desire to have a son, shared similar views for their daughters' protection. For instance, Tanu was in her mid-40s, and she shared similar views to Sonia. She explained that:

It is a tradition that there should be someone to take care of the sisters. No matter how many cousin brothers you have, a real brother is real. She [daughter] ties Rakhi [sacred thread that daughters tie at the wrist of their brothers] to her cousin brother as well, and he would help her even in the middle of the night if we would ask help from him, and he would always do this. Both of my sons [referring to her nephew] are good, but a real brother is real.

Tanu highlights that brothers play the role of a protector and that it is a social tradition. Similarly, Sana said:

Among us Hindus, there are so many festivals like Rakhi, which both daughter and son celebrate together. For my daughter, a brother was important and so she never had to think that she didn't have a brother.

Kanu was in her 60s she was highly educated, and had four children, three daughters and one son, with the wish of having a son.

So, I thought for them [daughters] that if they would have a brother for them where they wouldn't have to feel sad on Rakhi. They would have at least a place to visit after their parents' death.

The discussion of Rakhit in Tanu's, Sana's and Kanu's accounts contains a symbolic reference to the traditional socio-cultural duty of brothers towards their sisters and the social legitimacy of blood kinship. Many other participants had a son to provide a real brother to their daughters.

\section{DISCUSSION}

Both having a son and bringing dowry are culturally beneficial for women as individuals and raise their status in their affinal families, even though this highlights their socially subordinate position (Kabeer, 1999). But, dowry violence in contemporary times is being widely challenged by women, whereas the practice of son preference is not. All of my participants, for instance, considered dowry, unlike son preference, to be a severe form of violence against women.

Son preference has been normalised and naturalised to such an extent by the Indian women that only 1,165 cases of female foeticide have been filed in the whole country since the PCPNDT Act was implemented (Female Feticide, 2012). On the other hand, the reporting of cases of domestic violence and dowry abuse and murders are increasing. In 2007, for example, 8000 cases of domestic violence were registered, and it is important to note that the specific provision for domestic violence was implemented only in 2005 (Kasturi, 2008). Further, 8391 deaths

\footnotetext{
${ }^{4}$ Rakhi is the festival of Hindus in which the sister ties a sacred thread (called Rakhi) around the wrist of her brother and prays for his long and happy life, and in return the brother promises to be a life-long protector and supporter of his sister. 
were reported in India in the year 2010, which means one dowry death happens in every 90 minutes according to the report of Indian crime statistics ${ }^{5}$ (National Crime Records Bureau, 2011, p.195).

Dowry, as mentioned earlier, is commonly believed to be a strong reason behind son preference and daughter aversion. Smith et al.'s (2008), Unnithan-Kumar's (2010) and Mitra's (2014) studies among the rural and urban poor class South and North Indian women suggest that dowry and economic burden have fuelled daughter aversion. Unlike these studies, my research which looks at the educated North urban middle-class demonstrates that daughter aversion is not evident in this group; instead women want sons for their daughters or for their oldage or to enhance their status. Despite the prevalence of dowry practice the absence of dowry as a key reason behind son preference or daughter aversion is notable in the participants' accounts. This could be because in North India dowry is a vital way "of assessing and representing social status, honour and prestige" (Roulet, 1996, p.89). Also, nowadays urban middle-class daughters are highly educated and are earning enough that they are no longer an economic burden, but are able to contribute financially to their families (Belliappa, 2013; Kohli, 2017; Radhakrishnan, 2009). This means they can contribute towards their wedding and dowry expenses themselves. These changes are leading to an increase in daughters' status and the gradual decline of son preference. This situation can be viewed in the light of slowly improving child sex-ratios in Delhi and Haryana as recorded in the Indian Census 2011. For instance, in 2011, the female child sex ratio in Haryana increased by 15 points, rising to 834 from 819 in 2001 (Indian Census, 2001). Delhi has also witnessed a small increase in its child sex ratio rising three points, from 868 in 2001 to 871 in 2011 (Indian Census, 2001).

Ironically, despite these gradual changes in women's status, the women themselves played a key role in the legitimation of their own socio-cultural domination. Tulsi and Rita, for example, did not question son preference at all, and termed it natural, indicating that sons hold more socio-cultural values than daughters. Other participants such as Sonia, Tanu, Kanu and Sana legitimised male dominance under the idea of male protection for women; and Rama did not challenge the patriarchal ideology rather she wanted to gain the upper hand by having a son. Eventually, women will lose opportunities to be socially independent or take the role of social protectors and challenge male supremacy in their everyday lives. Kabeer (1999) argues that the practise of son preference by women shows that women tend to internalise their own subordination within patriarchal societies. The internalisation and acceptance of subordination, the imposition of gender inequality by women themselves, could be understood as a form of symbolic violence. Among the educated urban middle-class son preference is a form of symbolic violence as women will continue to be subordinated by holding a lower social status than men even in contemporary urban middle-class settings where women are educated have access to paid jobs and have laws to protect themselves (Kohli, 2017). They have financial and educational resources to challenge patriarchal practices; however, they have tended to practice son preference because of the socio-cultural associated benefits of having a son. "Women may not only accept their subordinate role to fit the so-called 'norm'; they may also choose that role because they are more likely to be valued and gain social acceptance" (Durey, 2008, p.8). Women's complicity to conform to gender hierarchy may also be shaped by their perceptions of the consequences if they resist. Challenging the traditional patriarchal beliefs often results in women facing social resistance and criticism within their social networks and families, and in some cases it can even result in divorce (Durey, 2008; Kabeer, 1999).

Women endeavoured to accumulate support for their daughters by having a son. By providing brothers to their daughters under the umbrella of socio-cultural beliefs and traditional gender roles women garnered cultural and social capital within their networks which were then converted to symbolic capital. These forms of capital are gendered and mainly stem from practising son preference, and accepting male supremacy and women's subordination. Symbolic violence suggests that power-relations are concealed and naturalised, and that through this, inequalities are reimposed within society (Bourdieu and Passeron, 1977; Köverová, 2010; Wacquant, 1998) in forms of popular values and beliefs. Gender hierarchy and patriarchal authority are reproduced and sustained in the daily lives of the urban middle-class in the name of care, love, protection and life-long support for sisters by brothers in urban India. These socio-cultural norms enforce the belief that women, no matter how much success they achieve in their career or education, will need men for protection in their daily lives.

Further, the popularity of small family has increased the use of ultrasound to determine the gender of the foetus among couples, as they want to limit their family size to two children (such as Tulsi and Tara) but want to have at least a son (Basu and Desai, n.d.; Unnithan-Kumar, 2010). Women are educated and employed, but this change has not resulted in the complete erosion of gender inequality and hierarchy among the urban middle-class.

\footnotetext{
${ }^{5}$ The high rate of dowry death suggests that dowry cases are still underreported. It is common to see that reports of dowry death are often made in those cases by the girls' family where the parents were pressuring their daughter to adjust in her affinal family even she made complaints of repeated incidences of violence towards her for not bringing sufficient dowry. Or in those cases where women would hide the cruelty they would face after their marriage from their maternal families.
} 


\section{CONCLUSION}

Gender inequality among the educated urban middle-class has undergone changes in modern times: girls are now being discriminated against before birth and not after birth. This marginal improvement signifies changing attitudes among the urban middle-class. The absence of daughter aversion among my sample suggests women's education and their financial contributions to the household is recognised and appreciated. Urbanisation, female education and employment are slowly changing the gender scripts so that daughters are increasingly perceived as being equally valuable to their families and societies.

The article demonstrates that physical violence is not necessary to control subordinated groups. Institutions such as family and marriage perpetuate the norms of gender inequality and reproduce them in daily interactions between men and women. The absence of a son leads family members and social networks to put pressure on women to have a son, affecting their reproductive choices. For example, participants considered socially constructed gender inequality as normal and natural and legitimised it through their son preference practice. As a result, the participants did not challenge their subordination and dependence upon men and instead considered themselves socially and biologically weaker and inferior to men.

Urban middle-class women have internalised their subordination to such an extent that they view their existence in relation to the men in their lives, be it in the form of a husband or a son or a brother. By accepting their subordinate status, women often receive socio-cultural benefits such as prestige and honour among their social networks and families, old-age support, financial support, and male protection. Simultaneously, they can protect themselves from forms of social criticism and resistance. These advantages increase women's status at the social level, but do not alter their subordinate position in society and the gender hierarchy.

Increases in female literacy enhance women's status which in turn curbs daughter aversion; however, these changes have so far failed to displace the practice of son preference. This demonstrates that traditional patterns of thinking are still prevalent and continue to define gender roles and practices especially among the middle-classes. Therefore, son preference, for the urban middle-class women is both a manifestation of symbolic violence and symbolic capital.

The limitations of this study are in the sample size: it is based on a small sample of 45 urban middle-class women's experiences in North India. However, it is clear these findings are relevant to women from different regions, castes, and classes in the rapidly changing contemporary Indian society. Further research is required to examine emerging trends in the context of son preference and daughters' status among the different class or caste groups in different regions of India. Hopefully, this work will inspire others to continue researching the intersection between gender, class, culture, and violence.

\section{REFERENCES}

Agnihotri, I. (2003). The expanding dimensions of dowry, The Indian Journal of Gender Studies, 10(2), 307-319. https://doi.org/10.1177/097152150301000206

Arnold, F. (2001). Son preference in South Asia. In Sathar, Z. \& Phillips, J. (eds.), Fertility Transition in South Asia (pp. 281-299). London: Oxford University Press.

Basu, A. M. and Desai, S. (n.d.). Middle class dreams: Indian's one child families. Available at: http://paa2010.princeton.edu/papers/101686 (Accessed 15 January 2018)

Belliappa, J. (2013). Gender, Class and Reflexive Modernity in India. London: Palgrave Macmillan. https://doi.org/10.1057/9781137319227

Bourdieu, P. (1986). The forms of capital, In J. C. Richardson (ed.). Handbook of Theory and Research for the Sociology of Education (pp. 241-258). London: Greenwood Press.

Bourdieu, P. (1990). The Logic of Practice. Cambridge: Polity Press.

Bourdieu, P. (2002). Distinction: A social critique of the judgement of taste. Cambridge, Massachusetts: Harvard University Press.

Bourdieu, P. and Passeron, J. C. (1977). Reproduction in Education, Society and Culture. London: Sage.

Bourdieu, P. and Wacquant, L I D. (2004). Symbolic violence. In N Scheper-Hughes and P I Bourgois (eds.), Violence in War and Peace: An Anthology (pp. 272-275), Oxford: Blackwell.

Brosius, C. (2011). The multiple bodies of the bride: Ritualising "World Class" at elite weddings in urban India. In A Michaels and C Wulf (eds.), Images of the Body in India (pp. 261-279). New Delhi: Routledge.

Census. (2011). Literacy in India, viewed 5th January 2016. Available at: http://www.census2011.co.in/literacy.php

Census. (2011). Missing...mapping the adverse child sex-ratio in India. Available at: http:/ / www.censusindia.gov.in/2011 census/missing.pdf (Accessed 14 January 2016)

Chandramouli, C. (2011). Rural urban distribution of population. Census of India 2011, Ministry of Home Affairs, Census of India, India. 
Chatterii, T. (2013). The micro politics of urban transformation in the context of globalisation: A case study of Gurgaon, India. South Asia: Journal of South Asian Studies, 36(2), 273-287. https://doi.org/10.1080/00856401.2012.739272

Clark, M. (2004). Men, masculinities and symbolic violence in recent Indonesian cinema. Journal of Southeast Asian Studies, 35(1), 113-131. https://doi.org/10.1017/S0022463404000062

Connolly, P. and Healy, J. (2004). Symbolic violence, Locality and social class: the educational and career aspirations of 10-11-year-old boys in Belfast. Pedagogy, Culture and Society, 12(1), 15-33. https:// doi.org/10.1080/14681360400200187

Dalmia, S. and Lawrence P. G. (2005). The Institution of dowry in India: Why it continues to prevail. The Journal of Developing Areas, 38(2), 71-93. https://doi.org/10.1353/jda.2005.0018

Dalmia, S., Lawrence Pareena, G. (2007). The Institution of Dowry in India: Why It Continues To Prevail. The Journal of Developing Areas, 38(2), 71-93. https:// doi.org/10.1353/jda.2005.0018

Das Gupta, M., Zhenghua, J., Li Bouha, X. Z. and Chung, B. H. W. (2003). Why is son preference so persistent in East and South Asia? A cross-country study of China, India and the Republic of Korea. Journal of Development Studies, 40, 153-187. https:// doi.org/10.1080/00220380412331293807

DiGiorgio, C. (2009). Symbolic violence. In A J Mills, G Durepos, and E Wiebe (eds.), Encyclopedia of Case Study Research (pp. 917-920). Thousand Oaks, CA: Sage.

Doherty, N. and Dickmann, M. (2009). Exposing the symbolic capital of international assignments. The International Journal of Human Resource Management, 20(2), 301-320. https:/ / doi.org/10.1080/09585190802670664

Donner, H. and Neve, G. D. (2011). Introduction. In H Donner (ed.). Being Middle Class in India: A Way of Life (pp. 1-22), London and New York: Routledge.

Durey, A. (2008). Rural medical marriages: Understanding symbolic violence in the social practice of gender. Women's Studies International Forum, 31(1), 73-86. https:// doi.org/10.1016/j.wsif.2007.11.003

Female Feticide. (2012). Rajasthan has maximum cases but no conviction, The Times of India, 13 May. Available at: http://articles.timesofindia.indiatimes.com/2012-05-13/jaipur/31689481_1_sonography-centres-pcpndt-actcases (Accessed 15 October 2012)

George, S. (1997). Female infanticide in Tamil Nadu, India: From recognition back to denial? Reproductive Health Matters, 5(10), 124-132. https://doi.org/10.1016/S0968-8080(97)90093-8

Goodkind, D. (1996). On substituting sex preferences strategies in East Asia: Does prenatal sex selection reduce postnatal discrimination? Population and Development Review, 22(1), 111-125. https://doi.org/10.2307/2137689

Guess, C. (2004). Decision making in individualistic and collectivist cultures. Online Readings in Psychology and Culture, 4(1), 2-18. https://doi.org/10.9707/2307-0919.1032

Ihlen, O. (2005). The power of social capital: Adapting Bourdieu to the study of public relations. Public Relations Review, 31(4), 492-496. https:/ / doi.org/10.1016/j.pubrev.2005.08.007

Indian Census. (2001). Gender composition. Available at: http://censusindia.gov.in/Census_And_You/gender_composition.aspx (Accessed 16 October 2016)

Jenkins, R. (1993). Pierre Bourdieu. London: Routledge.

Kabeer, N. (1999). Resources, agency, achievements: Reflections on the measurement of women's empowerment. Development and Change, 30(3), 435-464. https://doi.org/10.1111/1467-7660.00125

Kohli, A. (2012). Gang rapes and molestation cases in India: Creating mores for eve-teasing. Te Awatea Review, 10 (1 and 2), 13-17.

Kohli, A. (2017). Female education changes and continuation of gender roles in urban India. Economic and Political Weekly, LII(8), 61-66.

Konsky, C., Eguchi, M., Blue, J and Kapoor, S. (1999). Individualist-collectivist values: American, Indian and Japanese cross-cultural study. Intercultural Communication Studies, IX(1), 69-83.

Köverová, S. (2010). Sexual orientation as symbolic capital and as the "Object" of symbolic violence. Human Affairs, 20(1), 23-32. https://doi.org/10.2478/v10023-010-0003-2

Kasturi, C. S. (2008). Renuka tips for Mao vow. The Telegraph, 21st March. Available at: http://www.telegraphindia.com/1080321/jsp/nation/story_9043887.jsp (Accessed 13 February 2016)

McRobbie, A. (2004). Notes on 'What Not to Wear' and post-feminist symbolic violence. The Sociological Review, 52(2), 97-109. https://doi.org/10.1111/j.1467-954X.2005.00526.x

McRobbie, A. (2009). The Aftermath of Feminism: Gender, Culture and Social Change. London: Sage.

Miller, B. (1987). Female infanticide and child neglect in rural North India. In N S Hughes (ed.). Child Survival, MA: Kluwer Academic Publishers, 95-112. https://doi.org/10.1007/978-94-009-3393-4_5

Miller, B. (1997). The Endangered Sex: Neglect of Female Children in Rural North India. Delhi: Oxford University Press.

Mitra, A. (2014). Son Preference in India: Implications for Gender Development, Department of Economics, University of Oklahoma. 
Munshi, S. (2012). Education and dowry: An economic exploration. IIM Kozhikode Society and Management Review, 1(111), 111-120. https:/ / doi.org/10.1177/2277975213477269

National Crime Records Bureau. (2011). Crime in India statistics, Ministry of Home Affairs. Available at: http:/ / ncrb.nic.in/CD-CII2011/Statistics2011.pdf (Accessed 15 November 2012)

Pande, R. (2003). Selective gender differences in childhood nutrition and immunization in rural India: The role of siblings. Demography, 40(3), 395-418. https://doi.org/10.1353/dem.2003.0029

Patel, R. (2007). Hindu Women's Property Rights in Rural India: Law, Labour and Culture in Action, UK: Ashgate.

Radhakrishnan, S. (2009). Professional women, good families: Respectable femininity and the cultural politics of a “New” India'. Qualitative Sociology, 32(2), 195-212. https:// doi.org/10.1007/s11133-009-9125-5

Roulet, M. (1996). Dowry and prestige in North India. Contributions to Indian Sociology, 30(1), 89-107. https://doi.org/10.1177/006996679603000104

Sabarwal, S., McCormick, M. C., Subramanian, S. V. and Silverman J. G. (2012). Son preference and intimate partner violence victimization in India: Examining the role of actual and desired family composition. Journal of Biosocial Science, 44(1), 43-56. https:/ / doi.org/10.1017/S002193201100037X

Sekher, T. V. and Hatti, N. (2010). Disappearing daughters and intensification of gender bias: Evidence from two village studies in South India. Indian Sociological Society, 59(1), 111-133. https:// doi.org/10.1177/0038022920100106

Self, S. and Grabowski. (2009). Modernization, inter-caste marriage, and dowry: An analytical perspective. Journal of Asian Economics, 20(1), 69-76. https:/ / doi.org/10.1016/j.asieco.2008.07.001

Sharma, B.R., Gupta, N. and Relhan, N. (2007). Misuse of prenatal diagnostic technology for sex-selected abortions and its consequences in India. Public Health, 121(11), 854-860. https:/ / doi.org/10.1016/j.puhe.2007.03.004

Smith, N. D., Luke, N. and McGarvey, S. (2008). 'Too many girls, too much dowry': son preference and daughter aversion in rural Tamil Nadu, India. Culture, Health and Sexuality, 10(7), 697-708. https://doi.org/10.1080/13691050802061665

Sridharan, E. (2011). The growth and sectoral composition of India's middle classes: Their impact on the politics of economic liberalization. In A Baviskar and R Ray (eds.), Elite and Everyman: The Cultural Politics of the Indian Middle Classes (pp. 27-57), New Delhi: Routledge.

Srinivasan, P. and Lee, G. R. (2004). The dowry system in Northern India: Women's attitudes and social change. Journal of Marriage and Family, 66(5), 1108-1117. https://doi.org/10.1111/j.0022-2445.2004.00081.x

Srinivasan, S. and Bedi, A. (2007). Domestic violence and dowry: Evidence from a south Indian village. World Development, 35(5), 857-880. https://doi.org/10.1016/j.worlddev.2006.08.005

Swartz, D. (2012). Symbolic power and violence. In K Dowding (ed.). Encyclopedia of Power (pp. 648-649), Thousand Oaks: Sage.

Talwar, D. and Meenu. (2014). An analysis of literacy rate in Haryana. Journal of Business Management and Social Sciences Research, 3(7), 37-41.

Trammell, R. (2011). Symbolic violence and prison wives: Gender roles and protective pairing in men's prisons, The Prison Journal, 91(3), 305-324. https:/ / doi.org/10.1177/0032885511409891

Unnithan-Kumar, M. (2005). 'Introduction', in M Unnithan-Kumar (ed.), Reproductive Agency, Medicine and the State (pp. 1-24), New York, Oxford: Berghahn Books.

Unitthan-Kumar, M. (2010). Female selective abortion-beyond 'culture': Family making and gender inequality in a globalising India. Culture Health and Sexuality, 12(2), 153-166. https:/ / doi.org/10.1080/13691050902825290

Wacquant, L. (1998). Pierre Bourdieu. In R Stones (ed.). Key Sociological Thinkers (pp. 261-277), Basingstoke: Palgrave. https://doi.org/10.1007/978-1-349-26616-6_17

Weininger, E. B. and Annette, L. (2007). Cultural capital. In G Ritzer (ed.). Blackwell Encyclopedia of Sociology, Available at: http://www.sociologyencyclopedia.com/subscriber/tocnode.html?id=g-9781405124331_chunk_ g97814051243319_ss1-170. https://doi.org/10.1002/9781405165518.wbeosc169 